\title{
Electronic Funds Transfer Point Of Sale In Australia
}

\author{
Ralph Gyoery \\ Jennifer Seberry \\ University of Sydney
}

\section{ABSTRACT}

The Australia wide eftpos systems was developed by the Australian Retail Banks to meet Australian conditions including a small population, which overwhelmingly uses cash for transactions, a small number of banks capable of "exchange of value" settlements and enormous distances. This paper discusses the system that has evolved first involving only ATM's and banks, then extending to POS systems for retailers and non bank financial institutions. 


\section{An Introduction to Australian Banking.}

\subsection{Before Deregulation.}

The control of the Australian money supply was the responsibility of the Reserve Bank, a statutory body which had many powers such as setting the foreign exchange rate, issuing currency, issuing Australian Government bonds (thus determining interest rates), monitoring the monetary supply, determining the statutory deposit rate (the proportion of bank deposits which had to be deposited with the reserve bank) and generally guaranteeing the stability of the currency and banking system.

There were seven national and a small number of state banks which had licences to issue cheques and access to cheque clearing facilities and thus the exchange of value. All these banks had a large number of outlets so that in the cities there would be an outlet every one or two kilometres.

All these national banks had associated savings banks with which the general public could deposit funds, generally at a very low interest rate, and borrow funds for purchasing housing. Housing interest rates were controlled by the Government via the Reserve Bank. There were a small number of savings banks not associated with cheque issuing banks.

Savings banks only lent a maximum of $65 \%$ of the value of a house and so non-bank financial institutions, building societies arose. The general public made deposits with building societies by buying shares in the society. Societies lent up to $95 \%$ of the valuation of a house, at a slightly higher interest rate than savings banks, paid a higher interest rate on deposits and wrote customers cheques on the society account as required. They marketed their services aggressively and won considerable public support. Building societies also had a large number of outlets and longer opening hours than banks. 
Still there was a gap in the market for the provision of consumer finance other than via finance companies, mostly also associated with banks, which often charged extremely high interest rates. The banks met this opening by issuing an Australia wide indigenous credit card - the Bankcard.

The other main move into this market segment was via Credit Unions which were originally organisations based on a membership with some commonality of interest, e.g. working for a University or the public service. Members joined the Credit Unions by buying a share and thereafter could deposit and borrow funds at attractive rates. The Credit Unions, via EFT Pty Ltd, forced the pace of electronic banking in Australia, they market aggressively via T.V. and have wide consumer acceptance.

There was a small number of merchant or wholesale banks but these usually had only at most a handful of offices in Australia and were invisible to the general public. 
Figure 1: Australian Banking before Deregulation.

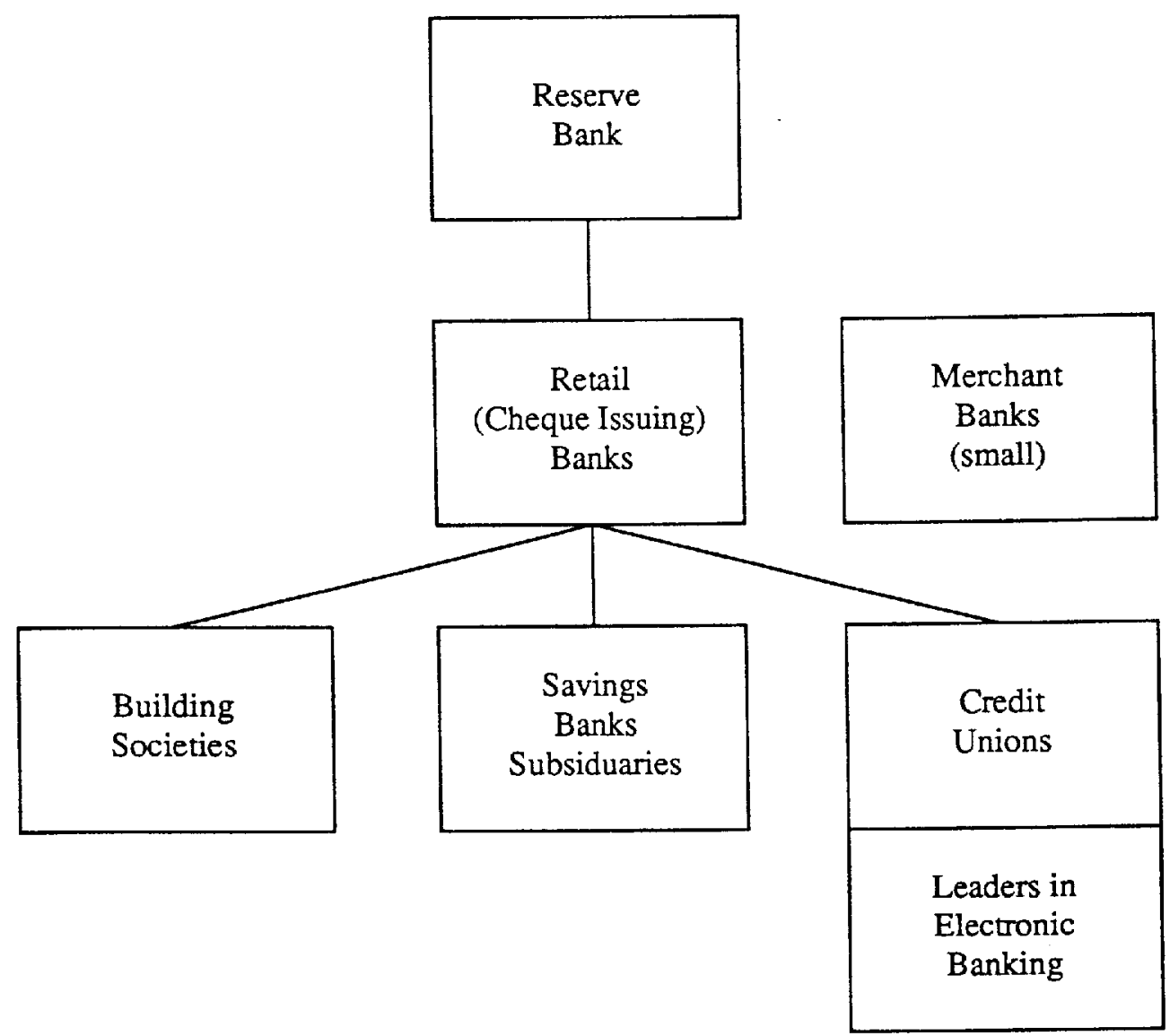




\subsection{After Deregulation.}

In the early 1980's it became apparent that there was considerable speculation against the Australian currency at a time when there was considerable volatility between the exchange rate of foreign currencies and high domestic inflation. This ultimately led to the Government's decision to deregulate the exchange rate and allow the Australian dollar to float in the international currency market.

At the same time the banks within Australia had an effective cartel so there was no competition. The Government announced that it would issue 16 new banking licences and that foreign banks would be able to apply for licences.

The indigenous banks would have to become bigger in order to survive in a world wide competitive market and there was a number of mergers leaving four major Retail Banks. Another cheque issuing bank (the State bank) which did not have a savings bank subsidiary acquired a building society, a building society issued a banking licence became a bank (the Advance bank) and other organisations issued licences are trying to acquire building societies in order to obtain retail outlets.

At the moment the four major Retail Banks, the ANZ, the Commonwealth, the National Australia and Westpac have extensive retail outlet networks in place gaining a major advantage in the Australian market.

Many building societies, some very large, survive as have credit unions and merchant banks. 
Figure 2: Australian Banking after Deregulation.
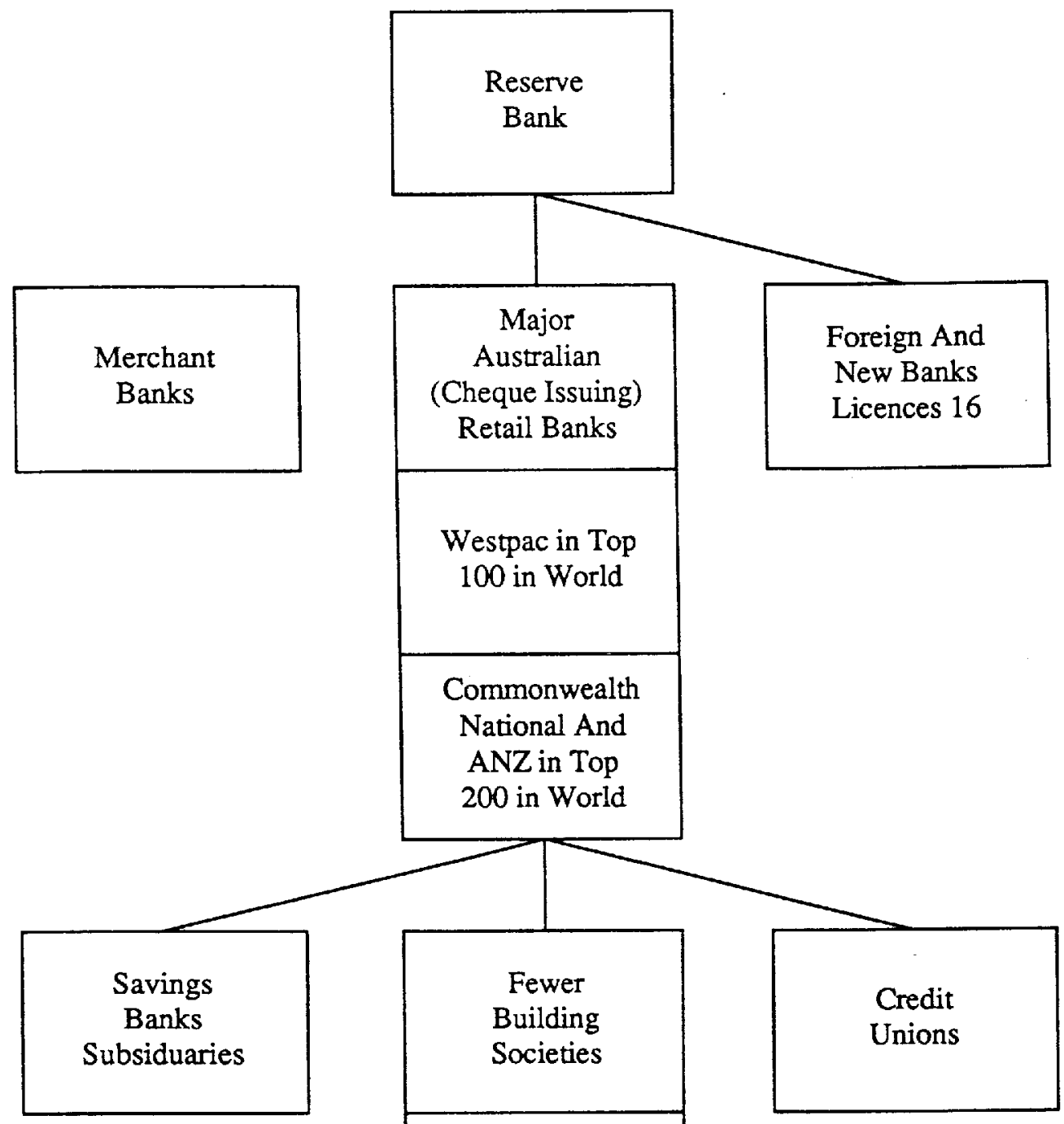

Old Building

Societies

Absorbed 


\subsection{Debit And Credit Cards.}

Bankcard, the indigenous credit card, has gained wide acceptance in Australia with 5.5 million cards issued to a population of 15 million.

Mastercard and Visa made an abortive entry to the Australian market in 1979-81 but were withdrawn. They re-entered the market, with different conditions attached in 1984 and have been aggressively marketed by some banks who wanted to discontinue Bankcard. Nevertheless Bankcard, which has very extensive market penetration in Australia and New Zealand survives.

All banks and non-bank financial institutions have issued debit cards for use with ATMs and POS. 


\section{Development of eftpos in the Australian Context.}

In the development of any commercial activity there are obviously a range of factors which are not only crucial to the establishment of the activity, but also its ongoing success. For convenience of classification, such factors can be defined as:

\section{Commercial/Strategic considerations}

2.Technical considerations

3.Socio-political considerations

The financial industry in Australia, like those in other countries, has undergone a process of rapid transformation over recent years. This transformation can, in large part, be attributed to two factors.

- The first is the move towards the deregulation of financial markets and,

- the second, increased utilisation and application of technology to a range of banking activities.

Within this environment, Australian Retail Banks have had to face two major challeriges.

First, the need to meet the intensification of competition between a range of financial institutions by providing customers with the services they demand. In particular at the retail end, convenient and speedy access to customer funds when and where they want them. 
Second, Australian Retail Banks have had to seek to contain and, over a period of time, reduce the cost pressures which operate on the organisations of their size.

Within Retail banking, eftpos plays a major role in both of these areas. The level of branch banking representation in Australia per head of population is significantly higher than most other countries. Eftpos is seen as an important means of reducing the reliance of the customer base on an expensive, labour intensive, and until currently, paper dominated, branch banking system.

The marketing thrust in this respect is to achieve a much lesser reliance, for simple debit and credit transactions, on the expensive one to one banking operation with its attendant reliance on paper documentation. The Australian Retail Banks have sought, therefore, to achieve a higher level of direct crediting of salaries to bank accounts. Once the Australian Retail Banks have this money, they are seeking to ensure that further transactions whether they be cash debits for food purchases; further credits or payment of regular accounts - occur electronically. The Australian Retail Banks are now looking to encourage their customer base to also to use Point Of Sale.

The importance of succeeding in this strategy of achieving a higher level of direct crediting of wages is revealed by the fact that approximately $70 \%$ of employees in Australia are still paid in cash. As a comparison - less than $5 \%$ of wage and salary earners in the USA, Canada and France are paid in cash. We note that in 1985 Australians used cash for $90 \%$ of all transactions.

For people to utilise a new form of financial delivery system - which is what eftpos is - some change in banking habits is required. It has been found that Australians - particularly young Australians - are not hesitant to use new technology in banking - eftpos provisors have had to ensure that the placement of POS terminals and the promotion of the overall eftpos system is well planned and executed to encourage utilisation. 
In this respect, market research has revealed that the largest outgoings from the household income, apart from mortgage or rent payments are for

- food and household goods, and for,

- petrol and other motor vehicle related expenses,

Further, research has indicated that people shop for food or buy petrol at least once a week.

As a result of this market research, locating eftpos terminals, particularly during the development phase, in retail outlets such as supermarkets and petrol stations, has been the most appropriate means of achieving the aim of providing customers with a delivery system which enabled the customers to gain access to their funds at convenient times and convenient locations.

When you consider that all four major Australian Retail Banks are actively involved in eftpos developments it becomes very clear that Australia has made a substantial commitment to this form of banking technology and is a significant way down the road to achieving a fully integrated system.

We will now consider the structure of the eftpos system in Australia. This is a subject of considerable importance and one which has excited considerable debate not only internationally but also in Australia.

There are a number of options or alternatives which were proposed in relation to the development of eftpos systems. While there are a range of variations, two of the major options can be defined as follows. 
First, there is a centrally owned and operated system, often called a single access system. This system could be controlled, for example, by a public utility; be owned by a private company or established as a consortium of various interests and groups. It is basically this structure which the British have been pursuing and which, we believe, is being developed in Singapore. In Australia it would have to be achieved by using Telecom Australia's Austpac Switching Network or a private switching network and be jointly administered by all participants.

Second, there is the approach initially being strongly advocated by the four major Australian Retail Banks. It is a decentralised system, known as the "gateway" structure, in which management and control of the machinery and switching system is in the hands of a number of players - in Australia's case the banks - that cooperate for the exchange of value. As initially proposed it was to be a closed system with retailers tied to their bank.

A central feature of the gateway approach to the development of EFT, particularly with reference to POS, is that it is a component in the exchange of value. Inherent in such an arrangement is the ability to guarantee to a receiving party that an exchange of value will occur consistent with a message transaction through the EFT system. The very concept of EFT is to transfer funds and this consideration had a bearing on the insistence of the four major Retail Banks that only they could guarantee the exchange of value.

The four major Australian Retail Banks were looking for an eftpos system which would, as far as practicable, be driven by market considerations and be market sensitive. They saw such a precondition as essential to the fulfillment of the requirements of the main participants in any eftpos system.

The Australian Retail Banks' belief that the gateway approach offered the best means for actually getting eftpos established in Australia was probably well founded. They foresaw that intractable delays and immense administrative, logistical and financial problems were associated with an approach which sought to bring together a range of interests and participants to 
develop a complex set of commercial arrangements.

The Banks had observed the United Kingdom experience, and believed it was both untenable and ultimately not in the best interests of the banks or their customers to attempt to duplicate what this country had set out to do. The Banks went into eftpos in an effort to gain a market advantage. Some of the Australian Retail Banks have obtained this market advantage, and at the same time, not sacrificed the ultimate integrity and viability of a fully operational and interlinked system between a wide range of financial institutions, retailers and consumers.

A major disadvantage to the gateway approach is the restrictions imposed on the market by excluding from or giving only limited access to new retail banks, non bank financial institutions such as building societies (which are a major source of housing finance), credit unions (which provide extensive services to members of cooperatives), merchant banks and insurance companies.

The gateway concept as initially advocated has now been modified in light of the vocal and valid criticisms by the non Retail Bank sector that it was being effectively excluded from the market and the Retail Traders Association that it did not adequately service all their customers. Agreement has now been reached that the eftpos terminals will accept all bankcards, debit and credit, as well as other cards such as American Express.

The major Ketail Banks saw the "gateway" leading to more rapid implementation breaking through the log jam of establishing a central system. They also saw the gateway as building incrementally on existing relationships between participants. The very essence of the gateway structure is a modular or incremental set of stages leading to full integration. The three main modular stages can be briefly described as follows. 
3. Modular Stages.

\subsection{Stage One.}

Stage one is a simple single connection between a retailer and a bank with only the cards issued by the participating bank being accepted. This is the stage Australia has already gone through. It is basically a process of experimentation, testing and verification.

\subsection{Stage Two.}

Stage two is an extension of the network to other settlement capable Australian Retail Banks, with the cards issued by those banks also being accepted. Note that we are talking about settlement capable financial institutions, which relates to our earlier point that eftpos is about the exchange of value. In Australia, it is only the banks which have this settlement capability, through our central bank - the Reserve Bank.

\subsection{Stage Three.}

Stage three further extends the network, this time to include other non settlement capable financial institutions. In Australia's case these are building societies and credit unions. Such institutions gain access to the system on an agency or sponsorship basis, whereby a bank undertakes to settle on their behalf.

Returning to the point of building on existing commercial arrangements between participants, one must realise that eftpos is first and foremost a set of complex commercial arrangements between the participants. One of the key strengths of the gateway structure is that it utilises existing relationships. These relationships can be identified as those:

- between a bank and retailer

- between a bank and the clearing house 
- an inter settlement capability between banks

- a relationship between a retailer and a non bank financial institution and, finally

- between an non bank financial institution and bank,

To illustrate this point, let us look at the initial part of the process - the relationship between a bank and retailer. In the case for Australian Retail Banks, one particular bank, Westpac, utilised an existing banking relationship with a supermarket chain, Woolworths Ltd, and extended it to the area of eftpos. The supermarket chain were confident that the eftpos system being introduced would be secure, reliable and, above all else, guarantee payment at the end of the day. Further, the supermarket chain was confident that if the bank entered into a relationship with another Retail Bank or non bank financial institution for the use of their plastic cards in the eftpos system, the same standards would apply and that they would still be assured of receiving value for transactions.

This incremental approach also offered a high degree of flexibility. It recognised that POS would ebb and flow as market forces determine the balance between demand and cost of provision. It also recognised - especially during the initial stages - that the different participants would wish to determine investment decisions, and to make decisions on longer term involvement on the basis of observing actual operation and development. The gateway structure allowed this to happen. It was not designed to lock participants in at the outset.

Another feature of the gateway system which is quite important to the private sector is it allows for the development of commercial relationships between participants based on market considerations. A fee structure could then be based on negotiation. Many Retailers, however, feared that the gateway, which controls access for other financial institutions, would effectively act as a Retail Bank cartel limiting free market operations. They foresaw that the banks would want them to pay for eftpos arguing that they provided retailers with access to their customer base. The Retailers argued that they 
made the sale and the banks should pay for the system. Neither wanted to pass the cost on to the customer who might them revert to paying cash.

The Australian Retail Banks expressed the view that the gateway could only be conducive to innovation and to the effective servicing of all participants - whether they were retailers, customers or the financial institutions.

Very little technical difficulty has been experienced with the majority of the terminals in operation in Australia. Customer usage of the system is increasing steadily, indicating that people are adapting to this form of technology. For example, the Combined Credit Unions Rediteller network, which was the first network of ATM's in Australia, was handling 7000 transactions per month in October 1985. Banks with ATM networks were handling 2-3000 transactions per month at that time.

Also in Australia we have the development of bilateral arrangements between financial institutions, such that the card of one institution is accepted at the terminal of another institution. In the case of Australia's non settlement capable institutions - the building societies and credit unions agency arrangements have been actively progressed between such institutions and banks. These arrangements were to ensure that the customers of non settlement institutions gained access to the eftpos system while the central element of that system - the guaranteed exchange of value - was maintained.

Let us now outline a few details of a particular eftpos system's operation in Australia. The system gives its customers access to their cheque account and savings account at retail outlets. At present about 4000 outlets are available in supermarket chains, chain stores and petrol retailers.

The customers can access their accounts to pay for goods and obtain some cash (if desired). The amount of cash that can be obtained is set by the individual retailer. For example, at the supermarket the sum of two hundred dollars cash can be obtained (US \$130), whereas at the petrol outlets the amount is thirty dollars (US $\$ 20$ ). In the supermarkets the terminals are 
located at the check-out lanes, while at the petrol outlets they are positioned at the service desks.

To operate the system the customer requires a plastic card particular to that financial institution, together with a four digit PIN (Personal Identification Number).

To use the system the customer hands his/her card to the cashier/operator who wipes the card through the terminal and then enters the amount of the transaction. The customer then authorises the transaction by entering his/her PIN through a separate hand-held key pad which we call the Pin Pad. The terminal then communicates with the financial institution's computer and the funds transferred from the account of the customer to the account of the retailer. This takes on average only fifteen seconds although transactions may be travelling up to 10,000 kilometres.

Upon successful completion of the transaction, the customer is issued with a printed receipt, details of the transaction (duplicate of which is held on the tally role in the terminal) are recorded on the customer's statement of account.

It should be noted that reliability and speed of the system is essential to both customer usage and retailer acceptance.

Up until March 1985, the financial institutions only provided a debit facility to its customers. Now there is the option for customers in States where regulations permit, to have access to their line of credit. 


\section{Technical Aspects Of Eftpos in Australia.}

The quality of any system is dependent on the quality of the constituent parts and the level of investment and expertise devoted to its development. This is certainly the case with eftpos which involves the transmission of financial information and which is, as such, an element of the payments process of a country.

The Australian Retail Banks have invested heavily in the area and required equipment and a system which guaranteed high reliability, high integrity and security of customer financial information.

LM Ericsson Pty Ltd., Burroughs and Fortronics have been responsible for fulfilling many requirements in relation to terminals which were required not only to be compact in size, but to be easy to use, fast in response time between terminal and host computer and have very secure in its encryption of raw data.

Transmission of messages between the terminal and the bank's computer system utilises either Telecom Australia's Austpac Switching Network, for the Commonwealth Bank and Westpac, or a private switching network, for the ANZ and National Australia Bank. Each Bank uses its own facilities as a frontend to large mainframes. The host provides on-line enquiry and updating facilities on customers' fund positions. The frontend also performs other functions, such as :

- Verification of customer Personal Identification Numbers

- Accumulation of individual merchant's settlement position, and

- The interchange of information between financial institutions. 
Figure 3: Commonwealth - Westpac System.

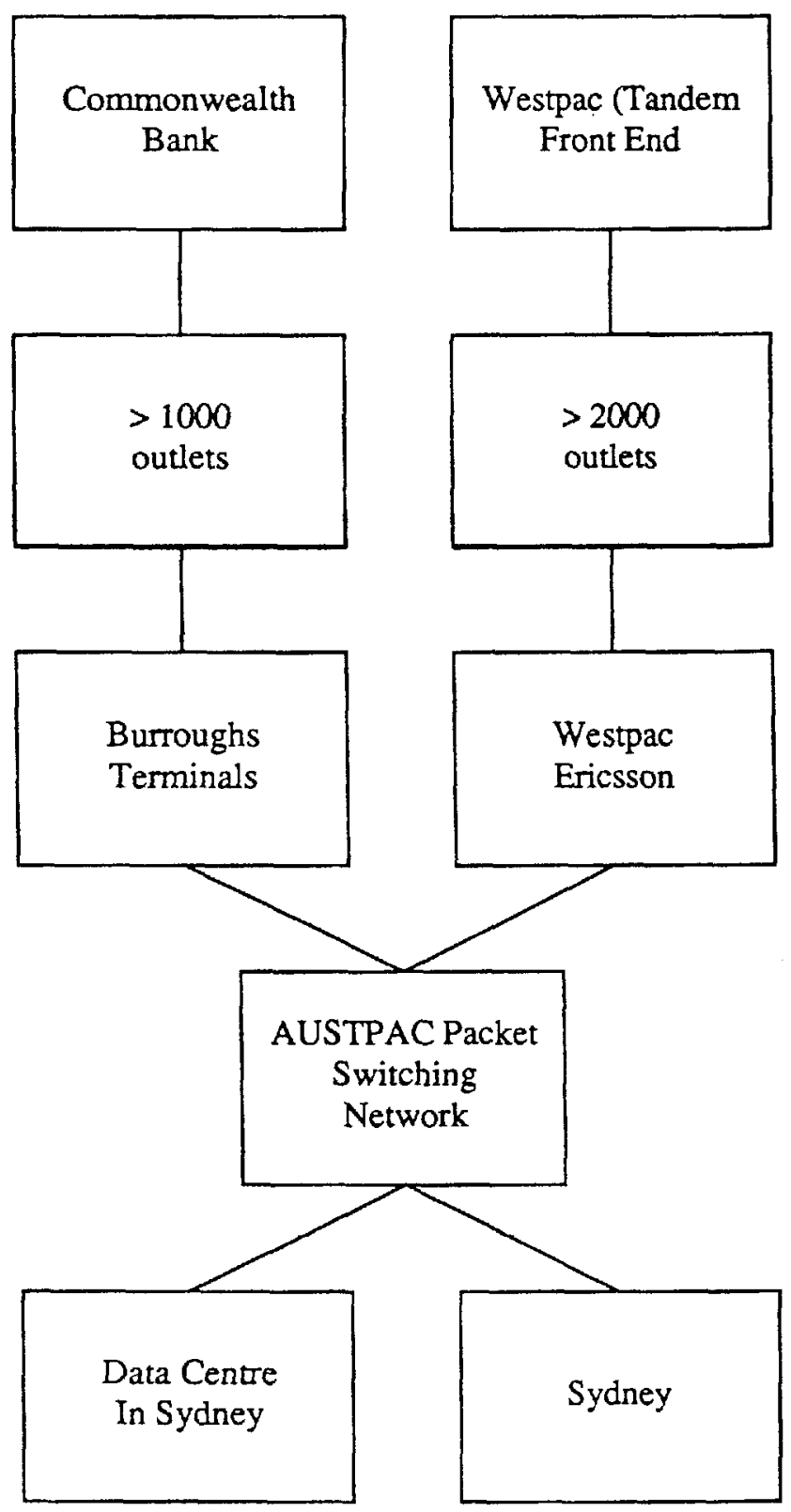


Figure 4: ANZ - National System.

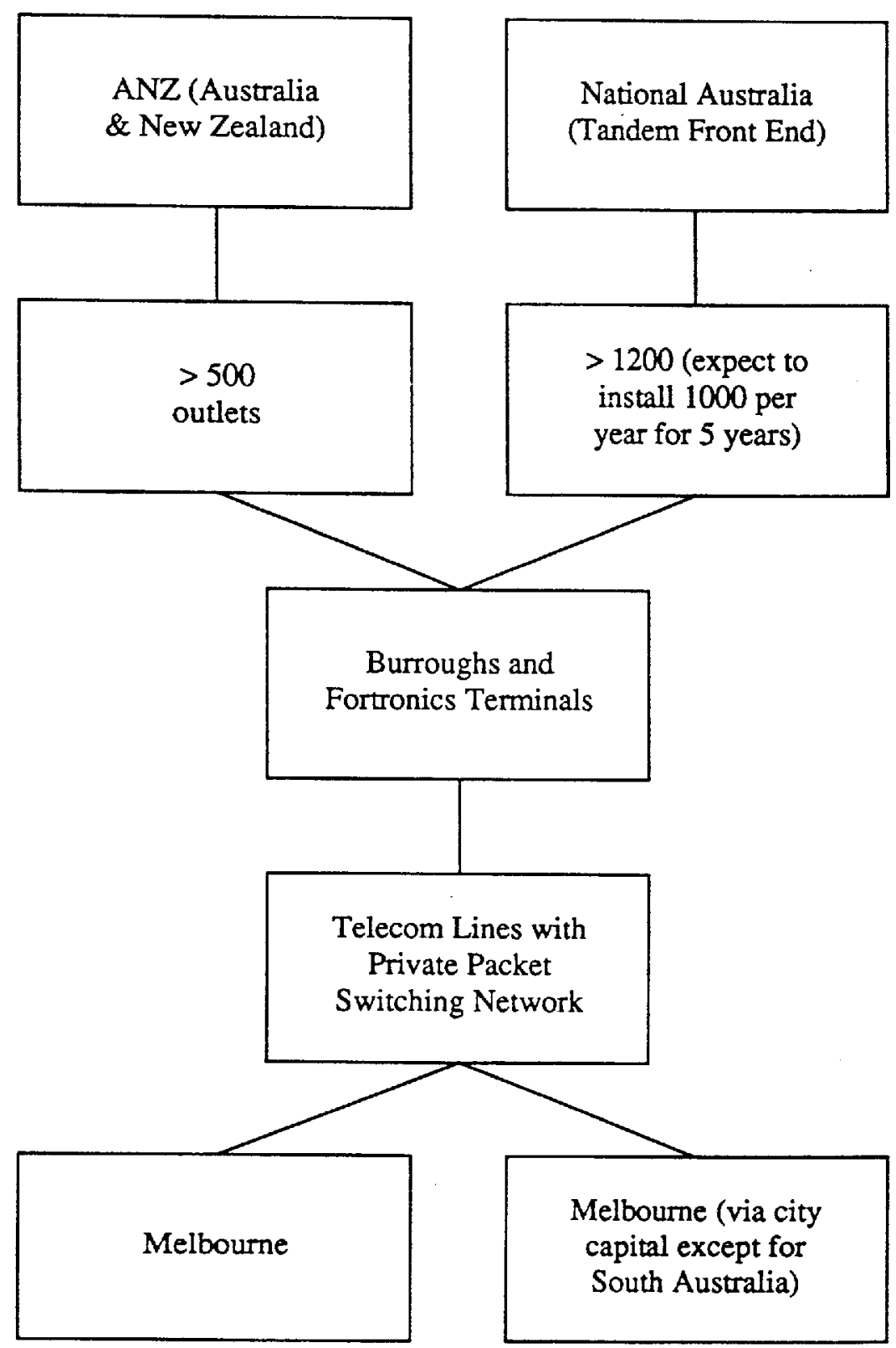




\section{Case Study - Westpac.}

The development of the Westpac eftpos system will be now given as a case study. The establishment of Westpac's eftpos system resulted from detailed planning and development over a nine month period. The first step in this exercise was the selection of a project manager and team encompassing key people from all areas :

- bank personnel from technical, operational and retail areas

- Telecom Australia responsible for the National Telecommunication Links; and

- Westpac's retail partners - Woolworths (Supermarket chain) and BP (petrol company).

The selection of a suitable equipment supplier was of prime importance in completing the project team. Although a number of POS systems (usually credit authorisation) were in operation in other countries, none met the requirements of the Australian environment. Westpac were looking for a supplier who would build a terminal to their specifications instead of offering a modified off-the-shelf solution.

LM Ericsson Pty Ltd had the requirements for the development of a terminal according to Westpac's specifications, which detailed the hardware and software requirements. Some of the major requirements were :

- compact in size (height and footprint to enable easy location at service desks and check-out lanes

- in built modem

- dot integrated printer

- low noise levels during operation 
- PIN pad no larger than a small calculator

- clear and easily understood display/prompts to both operator and customer

- quick response times between terminal and host computer to ensure fast service

- in short, Westpac wanted a terminal and PIN pad that was simple to use for both the operator and customer.

In addition, the overall security of the system was a key issue and a high standard of encrypted message formats were adopted to ensure "raw" data was not transmitted through communication links to Westpac's host computer. At no time during a transaction was any form of confidential customer detail to be displayed at the terminal.

The overall project was monitored with the use of critical path charts and action plans detailing the tasks of all parties. Development was not without problems but the planning and monitoring process highlighted shortcomings and enabled contingent actions to counteract potential delays.

A pilot launch of 20 terminals (10 in Woolworths and 10 in BP sites) commenced in April 1984, enabling Westpac to test the system in a live environment and iron out and errors before Westpac moved to any expansion of the network. The store managers and service station managers at the 20 pilot sites cooperated fully and were happy to use their respective sites as controls to trial this new technology.

From the experience of establishing the Westpac eftpos system, a few key points have surfaced, which should not be overlooked during the planning of any eftpos project :

- installation of communication link between retailer and bank. The physical connection is by the use of a dedicated line for the sole use of EFT messages and at certain retail premises, major alterations were required 
to permit installation. To avoid delays and unforeseen costs, availability of access should be considered, as well as allowing sufficient time for installation.

- testing of the system and equipment - prior to installation of any equipment, the entire system was subjected to extensive testing to eliminate the problems of a "live" environment. The live situation presented some problems. However with the cooperation of the 20 pilot sites, these were overcome in a short space of time (approximately three months). A close involvement and mutual commitment between retailer, Telecom and financial institution is essential for success.

- adequate training of financial institution and retailer staff is also an important pre-requisite. Customer usage of any form of "hands on" technology requires a degree of customer confidence. An encouraging employee, and associated educational campaigns, can greatly enhance this confidence, or, alternatively deflate it. This is backed up by a central "help desk" staffed by trained bank personnel. A phone call to the "help desk" provides immediate action to most situations.

- Site selection of POS terminals is clearly an important consideration. To ensure the best return on an investment, utilisation must be maximised. This can be achieved by careful site selection based on analysis of demographic movements and shopping habits.

- Adequate backup in the case of system malfunction is also something that must be closely considered in any new system. In Westpac's case, a simple paper-based back-up approach was introduced to deal with any system failures or disruptions.

- Final, the marketing and promotion of eftpos is essential. As with any retail product a clear marketing strategy must accompany the launch. Without this,eftpos starts well behind the barrier and will suffer the fate of any poorly marketed product. Incentive campaigns targeted at the card holders have been successful in improving awareness and encouraging use. 


\subsection{Key Factors For Success.}

In this section we will highlight some of the key issues of the planning, development and launching process as experienced by Westpac :

- Development Plan - This must include stretching but realistic time frames and objectives to ensure deadlines are achieved. Loose time frames will lead to delays.

- Total Commitment From All Parties - The absence of support from all concerned will inevitably result in delays and possibly failure.

- Retailer Involvement - As these people have a large influence on the success or otherwise of a project of this type, their input to the development process is considered mandatory.

- Reliable Equipment Supplier - Delivery where and when required is a must.

- Simplistic Design of Terminal - It is considered that ease of operation of the terminal can mear the difference between success or failure. Above all, the need for strong project management and control cannot be over emphasised.

\subsection{The Future For Westpac.}

Westpac is currently developing :

- Automated fuel pumps - the oil industry has expressed the need to relocate eftpos transactions from the shop to the forecourt of a petrol filling station. A card reader and PIN pad installed on the forecourt would provide customers with a fully self serviced facility - both petrol and eftpos

- Integrated cash registers - in this development the eftpos terminal would be fully integrated with the cash register and the electronic price 
scanning technology currently being developed. This has obvious advantages for retailers in terms of reducing space utilised and ensuring comprehensive inventory and financial control.

A major move by all Australian Retail Banks is to integrate their networks with the other bank networks thus allowing card holders of one bank to use the Automatic Teller machine of another bank. This is also an active area of development and installment for Westpac.

\subsection{Westpac Handyway System.}

June,82:

December,82:
Firmed up on concept

Negotiations with potential partners

Westpac wanted

- National Supermarket Chain.

- National Service Station Chain.

March,83: $\quad$ Firmed up negotiations with

- Woolworths and BP.

- Talked with potential terminal suppliers.

- Commenced negotiations with Telecom.

June, 83:

July,83:

December,83: $\quad$ Press release re POS project Westpac, BP, Woolworths. April,84:

Now:
Project formally approved by bank's executive committee and board. Project team set up.

Ericsson selected as terminal supplier. Tandem selected as front end.

Pilot launch 20 terminals in Sydney area.

- Expansion of Network

- Open access agreed to by all interested parties, interchange discussions, plans. 


\section{Socio-Political Aspects of Eftpos.}

Every commercial activity has the ability to affect the social and political environment or in turm be affected by it. Eftpos is certainly no exception and is perhaps a good example of how social and governmental factors can impact upon a commercial initiative.

Within Australia, the development of EFT, most notably in the area of POS, has been associated with the expression of a number of concerns within sections of the community and from some interest groups which seek to represent consumer interests. It has been suggested, often quite vociferously, that eftpos poses a serious threat to consumers in areas such as :

- security and confidentiality of financial information,

- liability in the event of a disputed transaction or system failure, and

- fraudulent usage.

The Australian Retail Banks have accepted the basis of such concerns as well intentioned even if they are not always based on an objective understanding of eftpos operations.

For example, it has been claimed that eftpos would allow a financial institution to build up a detailed picture of the purchasing habits of individuals. For example, in the event of an individual buying a device for the use of illicit substances, such as a water pipe for smoking marijuana, this information it has been claimed, could be made available to drug enforcement authorities.

The Australian Retail Banks have sought to face the social and governmental aspects of eftpos development responsibility and comprehensively. Discussions with consumer groups, administrators and politicians at all levels of government have been established to understand better their concerns and convey the views of the Australian Retail Banks. 
It has been argued by some that there is no established set of legislative arrangements to define rights and obligations for the providers and users of eftpos systems.

The Australian Retail Banks' view is that it is concerned to maintain the same, if not higher standards, relating to their relations with customers with EFT as with paper based transaction methods.

The Australian Retail Banks believe that legislation should only be contemplated if there is, or is likely to be, a demonstrable public need. To the extent that problems from a consumer point of view may arise, they would certainly prefer that these problems be tackled on a voluntarily or on the basis of an established and uniform industry code.

So far problems which have arisen such as

- consumers being held liable in the case of errors caused by mechanical and systems failures of the computer

- consumers being held liable for money issued in excess of their balances

have not always been perceived to have been handled fairly.

If there are any lessons to be learnt on this aspect of eftpos operation from Australia, it is that it is essential that the technical development and planning for eftpos be closely associated with a consideration of the policy and political aspects. To do this averts, or at least minimises, the potential for misunderstandings between the private sector and govermment and the consequent possibility of inhibiting legislative arrangements. 


\section{Advantages Of Eftpos To The Main Parties.}

\subsection{For The Australian Retail Banks.}

- Replacing paper with E.F.T (cost reducing)

- Better customer service

- Australian retail banks representation at retail outlets where customers shop and spend money

- Opportunities to broaden its customer base.

\subsection{For The Retailer.}

- Replacing paper with E.F.T (cost saving)

- Reduced cash (cost saving and better security)

- Better customer service

- Higher ticket sizes (increased sales)

- Same day value

- No bad debts

- No separate authorisation required

- Less physical security

- Access to Australian retail banks customer base. 


\subsection{For The Customer.}

- The major benefit for the customer is convenience - being able to access their accounts where and when they spend.

- Another important benefit is seen as less need to carry cash. 
8. The Future of Eftpos in Australia.

Agreement has now been reached so banks, non bank financial institutions, and retailers will all have complete access to the Australia wide eftpos network.

The linking up of ATMs is described in the diagram

Figure 5: Linking Up the ATMs (Sydney Morning Herald), 12/2/86.

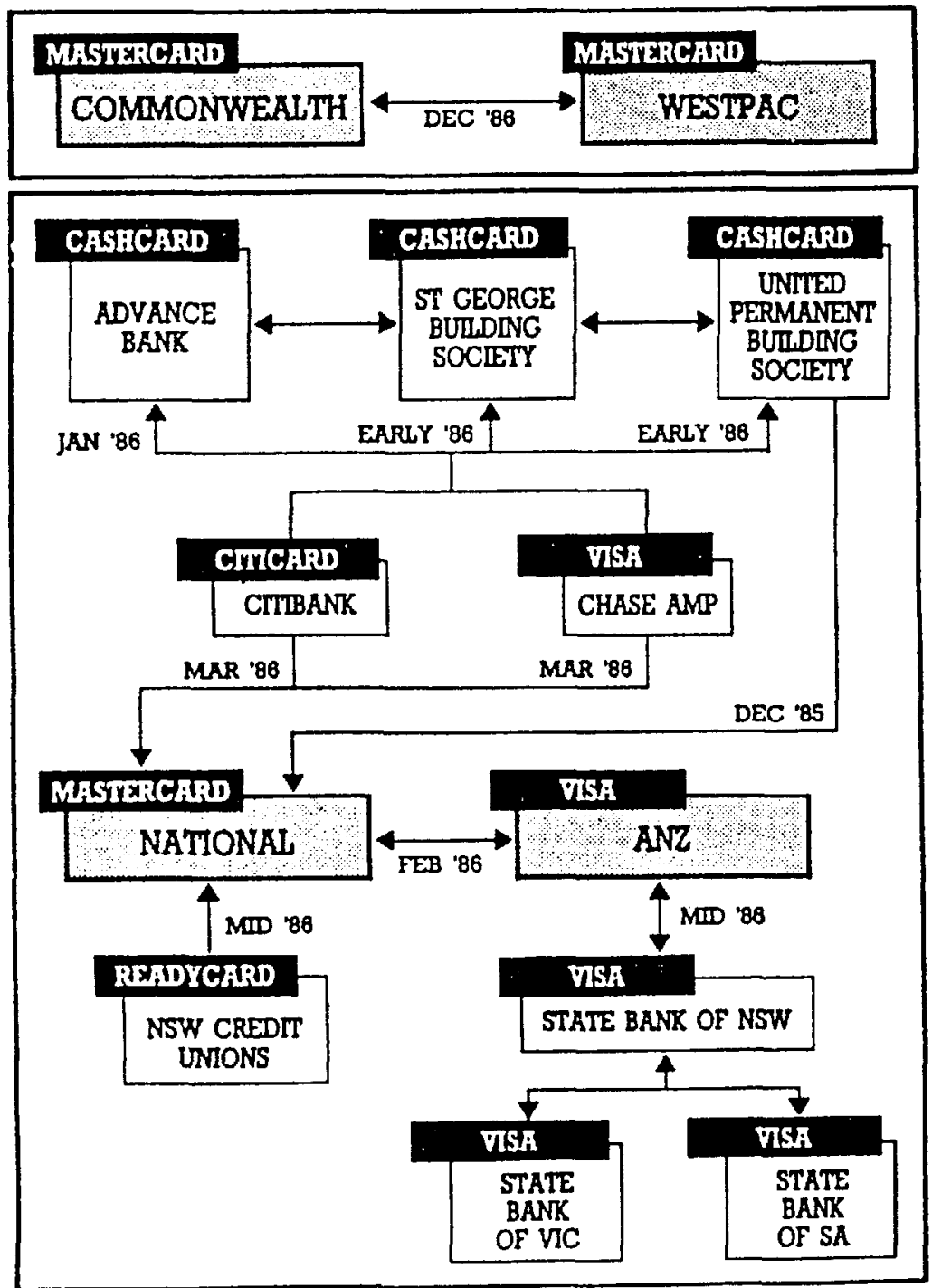




\section{Concluding Remarks.}

It is our opinion that eftpos marks a challenging and exciting development in the provision of retail banking services. After two years of debate, in mid July 1986, all the banks and the retailers agreed to eftpos. It is the future of retail banking and as such an integral means of improving customer services.

Security companies alarmed at the inroads to their business have been putting out TV commercials that try to illustrate the pure joy and beauty of cash. But we believe that the high acceptance of plastic money, with 5.5 million Bankcards for a population of 15 million people, and the acceptance of ATM's especially by the young, means they are too late to dam the flood.

Westpac and the Commonwealth Bank both have programs to allow children as young as 12-13 key cards to allow access to savings accounts. Unfortunately some families, who have not kept their PIN number secure from their children, have found their accounts drawn upon.

We expect to see in the future

- more terminals

- more merchants/retailers using the system

- extended POS interchange

- automated fuel pumps or driveway card acceptors

- electronic cash registers more widely used

- universal access to line of credit

- an extension of the facilities available via the eftpos network to include items such as brokerage, loans, investments, travel services, certificates of deposit . 


\section{References.}

[1] Gareth Powell and Gene Stephan, Banks, macro battle of the micro chips, Sydney Morning Herald, 14 October 1985.

[2] Anonymous, Eftpos standards pose challenge, Sydney Morning Herald, 14 October, 1985.

[3] Kester Cranswick, How Banks solve the cashless equation, Computing Australia, 18 November, 1985.

[4] Ben Bremner, Credit card fraud - it's growing, Sydney Morning Herald, 9 October 1985.

[5] Anonymous, Plastic money row on the cards as retailers challenge Banks, Sydney Morning Herald, 16 April 1986.

[6] Tony Healy, Fears ebb as eftpos banks on co-operation, Computing Australia, 7 July 1986.

[7] Keith Dunstan, Our cashless society heads back to the rum days, Sydney Morning Herald, 22 July 1986.

[8] Malcolm Wilson, Coming soon the card that goes anywhere, Sydney Morning Herald, 12 February 1986.

[9] Stephen Hutcheon, Pro-Bankcard forces plan services link, Sydney Morning Herald, 24 April 1986.

[10] Bill Paget, Implementing the Electronic Funds Transfer Point Of Sale System (EFTPOS) - Factors For Success, Speech delivered in Singapore, 1985. 